\title{
Üstün Yetenekli ve Normal Gelişen Çocukların Sınıf İçi Etkinliklere Yönelik Görüşleri
}

\section{Perceptions of Gifted and Typical Developing Children on Class}

\section{Activities}

\begin{tabular}{|c|c|}
\hline \multicolumn{2}{|r|}{ Fatma Betül Şenol, Selda Koca } \\
\hline Yazar Bilgileri & ÖZ \\
\hline $\begin{array}{l}\text { Fatma Betül Şenol } \\
\text { Arş. Gör. Dr., Afyon Kocatepe } \\
\text { Üniversitesi, Eğitim Fakültesi, } \\
\text { fbetululu@aku.edu.tr } \\
\text { Selda Koca } \\
\text { Öğretmen, Afyonkarahisar } \\
\text { Dumlupinar Bilim Sanat } \\
\text { Merkezi, seldak80@hotmail.com }\end{array}$ & $\begin{array}{l}\text { Çalışmada ilkokula devam eden üstün yetenekli ve normal gelişim gösteren çocukların sınıf } \\
\text { içi etkinliklerine yönelik görüşlerinin belirlenmesi ve karşlaştırılması amaçlanmıştır. } \\
\text { Araştırma betimsel nitelikte olup tarama modelinde bir çalışmadır. Araştırmanın çalışma } \\
\text { grubunu 2019-2020 eğitim-öğretim y1lı güz döneminde Afyonkarahisar Millî Eğitim } \\
\text { Müdürlüğg̈ne bağll Bilim Sanat Merkezine ve ilkokullara devam eden } 289 \text { çocuk } \\
\text { oluşturmaktadır. Veri toplama aracı olarak Sınıf Etkinliklerim Ölçeği kullanılmıştır. } \\
\text { Verilerin analizinde yüzde, frekans ve Mann Whitney U Testi kullanıllmıştır. Ölçekten alınan } \\
\text { puanlar üstün yetenekli çocuklarda 3,59-4,47 ve normal gelişim gösteren çocuklarda 3,79- } \\
4,11 \text { arasındadır. Üstün yetenekli ve normal gelişen çocukların puanları arasında istatistiksel } \\
\text { olarak anlamlı farklılık bulunmamıştır. Bu sonuçlar doğrultusunda, sınıf etkinliklerinin hem } \\
\text { üstün yetenekli çocuklar hem de normal gelişen çocukların gelişimlerini destekleyecek ve } \\
\text { sinıf etkinliklerine yönelik algılarının olumlu olmasını sağlayacak şekilde yapılandırılması } \\
\text { gerektiği söylenebilir. }\end{array}$ \\
\hline
\end{tabular}

\begin{tabular}{|c|c|}
\hline Makale Bilgileri & ABSTRACT \\
\hline Anahtar Kelimeler & In the study, it was aimed to determine and compare the perceptions of gifted and typical \\
\hline Üstün Yetenekli & developing children attending primary school towards class activities. This is a descriptive \\
\hline Sinıf Etkinlikleri & study designed in a scanning model. The study group of the research consists of 289 children \\
\hline İlgi & attending Science and Art Centre (BİLSEM) and primary schools affiliated to Afyonkarahisar \\
\hline Seçim & Provincial Directorate of National Education in the fall semester of the 2019-2020 academic \\
\hline Sinırları Zorlama & year. My Class Activities Survey was used as the data collection tool. Percentage, frequency \\
\hline Keyif & $\begin{array}{l}\text { and Mann Whitney U Test were used in the analysis of the data. The scores obtained from } \\
\text { the scale were found } 3.59-4.47 \text { in gifted children and } 3.79-4.11 \text { in typical developing children. }\end{array}$ \\
\hline Keywords & There was no statistically significant difference between the scores of gifted and typical \\
\hline Gifted & developing children. In line with these results, it can be said that class activities should be \\
\hline Class Activities & structured in a way that will support the development of both gifted children and typical \\
\hline Interest & developing children and ensure that their perception of classroom activities is positive. \\
\hline
\end{tabular}

Choice

Challenge

Enjoyment

\section{Makale Geçmişi}

Geliş: 05.05.2020

Düzeltme: 18.02.2021

Kabul: 02.03.2021 


\section{Giriş}

Çocukların öğrenme ortamlarına katılımlarının sağlanması öğrenme motivasyonları ile ilişkilendirilmektedir (Deniz ve Saranlı, 2017). Motivasyon, çocukların başarılı olmalarının kaynağıdır. Aynı zamanda çocukların belirli bir amaca yönelik bir davranışı edinmelerini sağlayan içsel ve dışsal faktörlerin tümüdür (Ertem, 2006). Öğrenme ve motivasyonun birbiri ile ilişkili kavramlar olduğu belirtilmektedir (Bacanlı ve Şahinkaya, 2011). Öğrenme ortamı, çocukların motivasyonları üzerine etkili olmaktadır (Gentry ve Gable, 2001). Çocukların motivasyonlarının düşük olması sınıf içi etkinliklere katılımlarını olumsuz etkilemekte ve sınıftaki öğrenme sürecine yoğunlaşamamalarına neden olmaktadır (Ersoy ve Başer, 2010). Bu nedenle öğretmenlerin çocukların motivasyonlarını arttırmak için değişiklikler yapması gerekmektedir. Bu değiş̧iklikler çocukların sınıf etkinliklerinden keyif almalarını, eğlenmelerini ve sınırlarını zorlamalarını sağlanmalıdır (Gentry ve Gable, 2001). Motivasyonu arttırmaya yönelik yapılan değişikliklerin normal gelişen çocuklar kadar üstün yetenekli çocuklar için de önem taşıdığı belirtilmektedir (Pereira, Bakhiet, Gentry, Balhmar ve Hakami, 2017).

Üstün yetenekli çocuklar, akranlarına göre bazı gelişim alanlarında üst düzey performans ve akranlarına göre farklı gelişim özellikleri gösterebilmektedirler (Davis, Rimm ve Siegle, 2011). Bazı gelişim alanlarında üstün performans gösterirken, bazı gelişim alanlarında tipik, bazı gelişim alanlarında ise daha düşük performans gösterebilmektedirler (Saranlı, 2017).

Üstün yetenekli çocukların sahip olduğu gelişimsel özellikler şöyledir: hafızaları güçlüdür, meraklıdırlar, dikkat süreleri uzundur, sabırsızdırlar, sözcük dağarcıkları geniştir, kapsamlı ifadeler kullanabilirler, hızlı öğrenirler, yaratıcıdırlar, sürekli soru sorarlar, soyut düşünebilirler, sıra dışı fikirleri ve farklı bir espri anlayışları vardır (Davis vd., 2011; Webb, Gore, Amend ve DeVries, 2007). Üstün yetenekli çocukların farklı gelişim özelliklerinin genel eğitim sınıflarında desteklenmesi ve potansiyellerinin en üst seviyeye çıartılması için farklı öğrenme ortamlarının sunulması, programın zenginleştirilmesi, kullanılan yöntem ve tekniklerin farklılaştırılması gerekmektedir (Park ve Oliver, 2009; Reid ve Horvathova, 2016). Üstün yetenekli çocuklar, uygun öğrenme ortamı sunulduğunda performanslarını gösterebilmektedirler (Sak, 2017). Üstün yetenekli çocuklara genel eğitim sınıflarında ilgilendikleri alanlarda, kendi sınırlarını zorlayarak ve keyif alarak yaptıkları çalışmaları içeren programlar sunulması gerekliliği uzun yıllardır vurgulanmaktadır (Reid ve Horvathova, 2016; Renzulli, 1994; Wright ve Ford, 2017).

Üstün yetenekli çocuklar ilgilendikleri alanlardaki konuları öğrenmek için daha fazla çaba göstermektedirler (Csikszentmihalyi, Rathunde ve Whalen, 1997; Renzulli vd., 2002), böylelikle daha kolay öğrenmektedirler (Singh, Granville ve Dika, 2002). Çocukların ilgilendikleri alanlara yönelik öğretimin sunulmasının öğrenme ile ilişkili olduğu belirtilmektedir (Singh vd., 2002). Bununla birlikte ilgi, motivasyon ile bağlantılı olan ve öğrenmeyi kolaylaştıran bir kaynak olarak açıklanmaktadır 
(Schiefele, 1991). İlginin çocukların daha başarılı olmalarında önemli bir etken olduğu vurgulanmaktadır (Wigfield ve Eccles, 2000). Çocukların ilgileri doğrultusunda hazırlanan eğitim ortamlarında kendi potansiyellerini geliştirmek için daha fazla çaba harcadıkları belirtilmektedir (Molden ve Dweck, 2000). Üstün yetenekli çocuklar için hazırlanan eğitim programlarında, çocukların ilgi alanlarına yer verilmesi (Renzulli, 1994), çocukların gelişimlerini ve potansiyellerini destekleyeceği düşünülmektedir.

Üstün yetenekli çocukların motivasyonlarına ve öğrenmelerine sınırları zorlama kavramı da etki etmektedir. Sınırları zorlama, çocukların yapabildiklerinin bir adım ilerisini yapmaya gayret göstermeleridir. Üstün yetenekli çocuklar yeteneklerine meydan okuyarak daha üst becerileri yapmaya çabalamakta ve kendi sınırlarını zorlayarak gelişimlerini destekleyebilmektedirler (Assouline, Colangelo, Ihrig ve Forstadt, 2006; McNabb, 2003). Ancak bu çocuklar, üstün yeteneklere sahip olma kimliklerini koruma eğiliminde olmaları nedeniyle sınırlarını zorlayan durumlarda başarısız olma riskini almamaktadırlar (Siegle, Rubenstein, Pollard ve Romey, 2010). Bu nedenle üstün yetenekli çocukların sınırlarını zorlayacakları zenginleştirilmiş ve farklılaştırılmış müfredatlar hazırlanması, problemlere kendi orijinal çözüm yollarını bulmalarının teşvik edilmesi, zor ve farklı düşünmelerini gerektiren soruların sorulmasının önemli olduğu belirtilmektedir (Bildiren, 2018; Renzulli, 1994).

Üstün yetenekli çocuklara ilgi alanları doğrultusunda seçim yapma olanağı sunulduğunda, çocuklar kendi öğrenmeleri üzerinde kontrol sahibi olmaktadırlar. Böylelikle çocukların içsel motivasyonları ve etkinliklere katılımları artmakta (Deci ve Ryan, 2008; Ryan ve Deci, 2002); kendi başlarına öğrenmeleri desteklenmektedir (Deniz ve Saranl1, 2017). Üstün yetenekli çocukların seçim yapmaları desteklendiğinde, çocukların etkinliklere daha iyi katılım gösterdikleri (Hospel ve Galand, 2016), motive oldukları (Frey ve Fisher, 2010) ve kendi başlarına önemli kararları alma becerilerinin geliştiği (Gentry ve Owen, 2004) belirtilmektedir. Üstün yetenekli çocukların eğitiminde çocukların seçimini dikkate almanın, çocuklara en uygun öğrenme deneyimi sunmak açısından önemli olduğu belirtilmektedir (Alexander ve Schnick, 2008). Çocuklar seçim yaparak ilgi alanları ile kendilerine sunulan eğitim programı arasında bağlantı kurmakta ve üst düzey başarıya ulaşabilmektedirler (Pereira, Peters ve Gentry, 2010).

Zevk alma, seçim ve ilgi ile ilişkili bir kavramdır (Pereira vd., 2010). Etkinlikler, çocuklar tarafından ilgi alanları doğrultusunda, kendi seçtikleri konu ile ilgili sınırlarını zorlayacak şekilde yapılandırıldığında, çocuklar etkinliklerden zevk almaktadırlar (Cash, 2011). Burada amacın eğlenmek değil, öğrenme etkinliğini çocuklara eğlenceli şekilde sunmak olduğu belirtilmektedir (Pereira vd., 2017). Çocuklara keyif alacakları, eğlenceli etkinlikler sunmak, çocuklara zevk ve memnuniyet vermekte (Gentry ve Gable, 2001), öğrenme performanslarını olumlu yönde etkilemekte 
(Pekrun, Goetz, Frenzel, Barchfeld ve Perry, 2011) ve çocukların etkinliklere ilgi duymasını sağlamaktadır (Gentry ve Gable, 2001).

Çocuklara sunulan sınıf içi etkinler çocukların ilgi alanları doğrultusunda, seçim yapma fırsatı sunarak, sınırlarını zorlayarak ve süreçten zevk almalarını sağlayarak gerçekleştirildiğinde çocukların öğrenmeye yönelik motivasyonlarının olumlu şekilde etkileneceği sonucuna ulaşılacağı belirtilmektedir (Pereira vd., 2017). Bu şekilde verilen eğitim, genel eğitim sınıflarında verilen geleneksel eğitimden farklılaşmaktadır. Çocuklara farklılaştırılmış bir eğitim ortamı sunmanın çocuklar için basit ancak etkili bir değişiklik olduğu değerlendirilmektedir. Tüm bunların hem normal gelişim gösteren hem de üstün yetenekli çocukların motivasyonunu ve öğrenme ortamını olumlu yönde etkilediği düşünülmektedir. Çocukların sınıf içi etkinliklere yönelik algıları öğretimin etkililiği hakkında önemli bilgiler sunmaktadır (Pereira vd., 2017). Bu nedenle normal gelişim gösteren ve üstün yetenekli çocukların sınıf içi etkinliklerine yönelik görüşleri incelenmesi gereken bir konu olarak karşımıza çıkmaktadır.

Türkiye'deki araştırmalar incelendiğinde, üstün yetenekli ve normal gelişen çocukların genel eğitim sınıflarındaki etkinliklere yönelik görüşlerini dört faktörün (ilgi, sınırları zorlama, seçim ve zevk alma) hepsini ele alarak karşılaştıran çalışma olmadığı görülmektedir. Uluslararası araştırmalar incelendiğinde ise üstün yetenekli ve normal gelişen çocukların görüşlerini karşılaştıran (Gentry, Gable ve Springer, 2000), üstün yetenekli çocukların görüşlerini inceleyen (Gentry, Rizza ve Gable, 2001; Gentry ve Gable, 2001; Pereira vd., 2010; Pereira vd., 2017) çalışmaların olduğu görülmektedir. Üstün yetenekli ve normal gelişen çocukların görüşlerinin belirlenmesinin ve karşılaştırılmasının, öğrenme ortamlarında çocukların özelliklerine göre değişiklik yapılabilmesi açısından önemli olduğu düşünülmektedir. Tüm bu açıklamalar doğrultusunda, çalışmada ilkokula devam eden üstün yetenekli ve normal gelişim gösteren çocukların sınıf içi etkinliklerine yönelik görüşlerinin belirlenmesi ve karşılaştırılması amaçlanmıştır. Bu amaç doğrultusunda aşağıdaki sorulara yanıt aranmıştır:

1. Üstün yetenekli ve normal gelişim gösteren çocukların sınıf içi etkinliklere yönelik görüşleri nedir?

2. Üstün yetenekli ve normal gelişim gösteren çocukların sınıf içi etkinliklere yönelik görüşleri arasında farklılık var mıdır?

\section{Yöntem}

\section{Araştırmanın Modeli}

$\mathrm{Bu}$ araştırma betimsel nitelikte, tarama modelinde bir çalışmadır. Betimsel çalışmalar, bir durumu/olguyu tanımlar. Tarama modeli, bir olayı/olguyu/durumu kendi koşulları içinde, olduğu gibi betimlemeyi amaçlayan çalışmalardır (Karasar, 2009). Bu çalışmada da üstün yetenekli ve normal 
gelişim gösteren çocukların sınıf içi etkinliklere yönelik görüşlerinin düzeyi ve bu çocukların sınıf içi etkinliklere yönelik görüşleri üzerinde farklılık olup olmadı̆̆ı araştırılmıştır.

\section{Çalışma Grubu}

Araştırmanın çalışma grubunu 2019-2020 eğitim-öğretim yılı güz döneminde Afyonkarahisar Millî Eğitim Müdürlüğüne bağlı Bilim Sanat Merkezine ve ilkokullara devam eden 289 çocuk oluşturmaktadır.

Bilim Sanat Merkezinde eğitim görmekte olan 142 üstün yetenekli çocuğa ulaşılmıştır. Birebir oranda 147 normal gelişim gösteren çocuk çalışmaya dâhil edilmiştir. Üstün yetenekli çocukların \%50,00'si kız, \%50,00'si erkektir. Çocukların \%21,13'ü ikinci sınıfa, \%35,92'si üçüncü sınıfa, \%42,96'sı dördüncü sınıfa devam etmektedir. Çocukların \%5,63'ü yedi, \%26,76's1 sekiz, \%38,73'ü dokuz, $\% 26,06$ 'sı on, $\% 2,82$ 'si ise on bir yaşındadır.

Normal gelişen çocukların \%51,02'si kız, \%48,98'i erkektir. Çocukların \%23,81'i ikinci sınıfa, \%37,41'i üçüncü sınıfa, \%38,78'i dördüncü sınıfa devam etmektedir. Çocukların \%10,88'i yedi, $\% 29,25^{\prime}$ i sekiz, \%27,21'i dokuz, \%31,29'u on ve \%1,36'sı on bir yaşındadır.

\section{Veri Toplama Araçları ve Süreci}

\section{Sınıf Etkinliklerim Ölçeği (My Class Activities Survey):}

Ölçek, çocukların sınıftaki etkinliklere ilgi duyma, zevk alma, sınırları zorlama ve seçim yapabilmelerine yönelik algılarını tespit etmek amacılla Gentry ve Gable (2001) tarafından geliştirilmiş, Deniz ve Saranlı (2017) tarafından Türkçeye uyarlanmıştır. Ölçek 32 maddeden ve ilgi duyma, seçim yapabilme, sınırlarını zorlama ve konudan zevk alma olmak üzere toplam dört alt boyuttan oluşmaktadır. Ölçek beşli likert tipinde ("Hiçbir Zaman” (1) ile "Her Zaman” (5) arasında) tasarlanmıştır. Gentry ve Gable (2001) ölçeğin Cronbach Alfa iç tutarlılık katsayısını İlgi Duyma, 0,89; Sınırları Zorlama, 0,78; Seçim Yapabilme, 0,75; Keyif Alma, 0,92; Deniz ve Saranlı (2017) ise sırasıyla $0,86,0,82,0,83$ ve 0,90 olarak hesaplamıştır. Bu çalışmada ise sırasıyla $0,82,0,80,0,86$ ve 0,83 olarak hesaplanmıştır.

Veriler 2019-2020 eğitim-öğretim yılı güz döneminde Afyonkarahisar Millî Eğitim Müdürlügünden izin alınarak; Bilim Sanat Merkezine ve ilkokullara devam eden çocuklara uygulanmıştır. Uygulama öncesinde çalışma ve ölçme aracı hakkında çocuklara ve ailelerine bilgi verilmiş, onamları alınmış ve ölçek uygulanmıştır.

\section{Verilerin Analizi}

Demografik özelliklerin değerlendirilmesinde yüzde ve frekans dağılımları kullanılmıştır. Çalışma grubundaki çocukların Sınıf Etkinliklerim Ölçeği'nden aldıkları puanları belirlemek amacıyla Kolmogorov-Smirnov normallik testi uygulanmış ve normal dağılım göstermediği tespit edilmiştir. 
Gruplar arası farklılık incelenirken ikili gruplar için Mann Whitney U Testi uygulanmıştır. Anlamlılık düzeyi olarak 0,05 olarak kabul edilmiştir (Büyüköztürk, Kılıç-Çakmak, Akgün, Karadeniz ve Demirel, 2011).

\section{Araştırmanın Etik İzinleri}

Yapılan bu çalışmada Afyon Kocatepe Üniversitesi Sosyal ve Beşeri Bilimleri Araştırma ve Yayın Etiği Kurulundan onay alınmış ve "Yükseköğretim Kurumları Bilimsel Araştırma ve Yayın Etiği Yönergesi" kapsamında uyulması belirtilen tüm kurallara uyulmuştur. Yönergenin ikinci bölümü olan "Bilimsel Araştırma ve Yayın Etiğine Aykırı Eylemler" başlığı altında belirtilen eylemlerden hiçbiri gerçekleştirilmemiştir.

\section{Bulgular}

İlkokula devam eden üstün yetenekli ve normal gelişim gösteren çocukların sınıf içi etkinliklerine yönelik görüşlerinin belirlenmesi ve karşılaştırılması amacıyla yapılan çalışmanın bulgularına aşağıda yer verilmiştir.

Tablo 1. Üstün Yetenekli ve Normal Gelişen Çocukların SEÖ’den Aldıkları Puanlar ve Karşılaştırılması

\begin{tabular}{|c|c|c|c|c|c|}
\hline SEÖ & Gruplar & $X-S s$. & E.K.-E.B & $U$ & $p$ \\
\hline \multirow{2}{*}{ İlgi } & Üstün Yetenekli & $4,02-0,66$ & $1,00-5,00$ & \multirow{2}{*}{9569} & \multirow{2}{*}{0,221} \\
\hline & Normal Gelişen & $4,11-0,69$ & $1,56-5,00$ & & \\
\hline \multirow{2}{*}{$\begin{array}{l}\text { Sinırları } \\
\text { zorlama }\end{array}$} & Üstün Yetenekli & $4,07-0,63$ & $1,56-5,00$ & \multirow{2}{*}{10364} & \multirow{2}{*}{0,917} \\
\hline & Normal Gelişen & $4,06-0,73$ & $2,11-5,00$ & & \\
\hline \multirow{2}{*}{ Seçim } & Üstün Yetenekli & $3,59-1,07$ & $1,00-5,00$ & \multirow{2}{*}{9510} & \multirow{2}{*}{0,191} \\
\hline & Normal Gelişen & $3,79-0,90$ & $1,14-5,00$ & & \\
\hline \multirow{2}{*}{ Keyif } & Üstün Yetenekli & $4,47-0,63$ & $1,57-5,00$ & \multirow{2}{*}{10207} & \multirow{2}{*}{0,742} \\
\hline & Normal Gelişen & $4,37-0,74$ & $1,00-5,00$ & & \\
\hline \multirow{2}{*}{ Toplam } & Üstün Yetenekli & $4,04-0,60$ & $1,28-5,00$ & \multirow{2}{*}{10066} & \multirow{2}{*}{0,601} \\
\hline & Normal Gelişen & $4,08-0,61$ & $2,50-5,00$ & & \\
\hline
\end{tabular}

Tablo 1'de üstün yetenekli ve normal gelişim gösteren çocukların Sınıf Etkinliklerim Ölçeği'nin alt boyutlarından ve toplamından aldıkları puanlar incelendiğinde, istatistiksel olarak anlamlı farklılık olmadığı görülmektedir $(p>0,05)$.

Tablo 2. Üstün Yetenekli ve Normal Gelişim Gösteren Çocukların SEÖ’nün Maddelerinden Aldıkları Puanların Karşılaştırılması

\begin{tabular}{|c|c|c|c|c|}
\hline Maddeler & Gruplar & Ort-ss. & $u$ & $p$ \\
\hline \multirow{2}{*}{$\begin{array}{l}\text { 2. Sınıfta ilgimi çeken konular üzerinde } \\
\text { çalışma fırsatım olur }\end{array}$} & Üstün Yetenekli & $3,61-1,10$ & \multirow{2}{*}{8945,0} & \multirow{2}{*}{$0,029^{*}$} \\
\hline & Normal Gelişen & $3,86-1,17$ & & \\
\hline \multirow{2}{*}{ 4. Sinıfta yaptıklarım bana yeni fikirler verir. } & Üstün Yetenekli & $4,09-1,00$ & \multirow{2}{*}{9026,5} & \multirow{2}{*}{$0,031^{*}$} \\
\hline & Normal Gelişen & $4,33-0,91$ & & \\
\hline \multirow{2}{*}{$\begin{array}{l}\text { 5. Sınıfta ilgi çekici konular üzerinde } \\
\text { çalışırım. }\end{array}$} & Üstün Yetenekli & $3,49-1,14$ & \multirow{2}{*}{ 7991,0 } & \multirow{2}{*}{$<0,001^{*}$} \\
\hline & Normal Gelişen & $3,95-1,07$ & & \\
\hline \multirow{2}{*}{$\begin{array}{l}\text { 9. Sınıftaki etkinlikler ilgilerimi keşfetmeme } \\
\text { yardımcı olur }\end{array}$} & Üstün Yetenekli & $3,92-1,03$ & \multirow{2}{*}{9107,0} & \multirow{2}{*}{$0,048^{*}$} \\
\hline & Normal Gelişen & $4,10-1,08$ & & \\
\hline \multirow{2}{*}{$\begin{array}{l}\text { 21. Sınıf etkinliklerindeki grup çalışmasında, } \\
\text { grup arkadaşlarımı kendim seçebilirim. }\end{array}$} & Üstün Yetenekli & $3,34-1,45$ & \multirow{2}{*}{8759,0} & \multirow{2}{*}{$0,014^{*}$} \\
\hline & Normal Gelişen & $3,72-1,47$ & & \\
\hline
\end{tabular}


Tablo 2'de üstün yetenekli ve normal gelişim gösteren çocukların Sınıf Etkinliklerim Ölçeği'nden aldıkları puanlar madde bazında karşılaştırıldığında; 2, 4, 5, 9 ve 21. maddelerde normal gelişim gösteren çocukların lehine istatistiksel olarak anlamlı farklılık olduğu görülmektedir $(p<0,05)$. Diğer maddelerde ise istatistiksel olarak anlamlı farklılık bulunmamıştır.

\section{Tartışma ve Sonuç}

Öğrenme ortamlarında çocukların motivasyonlarını artırmak, sınıf etkinliklerine katılımlarının artmasının anahtarıdır (Ortiz, 2018). Çocukların öğrenme ortamlarına yönelik motivasyonlarının artmasında, sınıf etkinliklerinin içeriği önem taşımaktadır. Bu nedenle özellikle üstün yetenekli çocukların gelişimlerini destekleyen ve olumlu öğrenme ortamlarının oluşturulmasına etki eden faktörlerin üzerinde durulması gerekmektedir (Brigandi, Weiner, Siegle, Gubbins ve Little, 2018). Çalışmanın sonucunda, üstün yetenekli ve normal gelişim gösteren çocukların sınıf içi etkinliklere yönelik görüşlerinin yüksek düzeyde olduğu tespit edilmiştir. Gentry ve Gable'ye (2001) göre Sınıf Etkinliklerim Ölçeği'nden alınan yüksek puanların çocukların sınıf etkinliklerine yönelik algılarının olumlu olduğunu göstermektedir. Çalışmada çocukların ölçekten aldıkları yüksek puanlar genel eğitim sınıflarını ilgi çekici, zevkli, seçim yapılabilen ve sınırlarını zorlayan ortamlar olarak düşündükleri söylenebilir. Sınıf etkinlikleri çocuklar için ilgi çekici, zevkli, seçim yapmaya müsait ve sınırlarını zorlayıcı şekilde planlandığında çocukların öğrenme ortamından daha fazla verim aldıkları belirtilmektedir (Wright ve Ford, 2017). Bu çalışmadan alınan yüksek puanlar, eğitim ortamının hem üstün yetenekli hem de normal gelişim gösteren çocuklar için verimli ortamlar olduğunu gösterdiği söylenebilir.

Sınıf içi etkinlikleri değerlendiren Pereira vd.'nin (2017) yaptıkları çalışmada 2-8. sınıfa devam eden üstün yetenekli ve normal gelişim gösteren çocukların Sınıf Etkinliklerim Ölçeği'nden aldıkları puanların yapılan bu çalışmaya göre düşük olduğu görülmektedir. Bu durumun çalışma gruplarındaki çocukların katıldıkları eğitim ortamlarının ve sosyo-kültürel durumun farklı olmasından kaynaklandığı düşünülebilir. Eğitim ortamlarında yapılan değişikliklere ilişkin bir başka çalışma incelendiğinde, 3-8. sınıflara devam eden ve cumartesi zenginleştirme programına katılan üstün yetenekli çocukların Sınıf Etkinliklerim Ölçeği'nden aldıkları puanların yüksek olduğu sonucuna ulaşılmıştır (Pereira vd., 2010). Yapılan bu çalışmaya katılan üstün yetenekli çocukların da Pereira vd.'nin (2010) çalışmasında kullanılan programa benzer şekilde BİLSEM tarafından oluşturulan programlara katıldıkları için çocukların puanları benzer şekilde yüksek bulunmuştur. Çünkü üstün yetenekli çocuklar ilgilerini çeken ve zevk aldıkları öğrenme ortamlarında daha iyi motive olmaktadırlar (Brigandi, Siegle, Weiner, Gubbins ve Little, 2016). Üstün yetenekli çocuklar BİLSEM'de ilgi alanları doğrultusunda sınırlarını zorlayan eğitim aldıkları, bu süreçte seçim yapma fırsatı sunulduğu ve aldıkları eğitimden zevk aldıkları için puanlarının daha yüksek olduğu, sınıf içi 
etkinliklere yönelik algılarının olumlu yönde etkilendiği düşünülebilir. Yapılan bu çalışmada normal gelişim gösteren çocukların puanlarının da yüksek olması, öğretim ortamlarında teknolojik araç gereçlerin kullanılması, materyallere ulaşım kolaylığı, eğitimin çocukların bireysel farklılıklarını dikkate alarak gerçekleştirilmesinden kaynaklandığı değerlendirilmektedir.

Üstün yetenekli çocukların birçok alanda normal gelişen akranlarına göre farklı özellikler taşıdığı belirtilmektedir (Roeper ve Silverman, 2009). Bu nedenle üstün yetenekli ve normal gelişim gösteren çocukların genel eğitim sınıflarındaki etkinliklere yönelik görüşleri karşılaştırılmış ve aralarında anlamlı farklılık olmadığı tespit edilmiştir. Ölçekten alınan puanlar incelendiğinde, üstün yetenekli ve normal gelişim gösteren çocukların sınıf etkinliklerine yönelik görüşlerinin birbirine yakın olduğu görülmüştür. Çocukların ölçekten aldıkları puanlar madde bazında incelendiğinde ise, ilgi (madde 2, 4, 5), sınırları zorlama (madde 9) ve seçim (madde 21) alt boyutlarındaki bazı maddelerde normal gelişen çocukların lehine anlamlı farklılık olduğu belirlenmiştir. Üstün yetenekli çocukların maddelerin bir kısmından düşük puan almaları genel eğitim sınıflarında sıkıldıklarına, zevk almadıklarına ve ilgi duymadıklarına ilişkin bir işaret olabileceği değerlendirilmektedir. Üstün yetenekli olan ve olmayan ortaokula devam eden çocuklarla yapılan bir çalışmanın sonucunda, çocukların sınıf etkinliklerine yönelik görüşlerinin birbirine yakın olduğu görülmüş ve seçim alt boyutunda gruplar arası anlamlı farklılık olduğu tespit edilmiştir (Gentry vd., 2000). Yang, Gentry ve Choi (2012) 3-6. sınıfa devam eden üstün yetenekli ve normal gelişim gösteren çocukların sınıf etkinliklerine yönelik algılarını inceledikleri çalışmada; üstün yetenekli çocukların, normal gelişim gösterenlere göre ilgi, seçim yapma ve zevk alma alt boyutlarında yüksek; sınırları zorlama alt boyutunda ise farklılık olmadığı sonucuna ulaşmıştır. Sınırları zorlama alt boyutunda farklılık çıkmasının nedenini öğretmenlerin tüm çocuklara aynı zorluk seviyesinde öğrenme ortamı sunmasından kaynaklanabileceğini belirtmişlerdir. Ayrıca üstün yetenekli çocukların sınıfta normal gelişen çocuklara göre yeni konuları daha çok merak ettikleri ve ilgilendikleri sonucuna ulaşılmıştır (Davis vd., 2011). Elde edilen bu sonuçların genel eğitim sınıflarında çocuklara sunulan öğrenme ortamları ile ilişkili olduğu söylenebilir. Genel eğitim sınıflarında üstün yetenekli çocuklar için çok az farklılık yapıldığı yapılan araştırmalarda belirtilmiştir (Archambault vd., 1993; Westberg, Archambault, Dobyns ve Salvin, 1993). Bununla birlikte üstün yetenekli çocuklar ilkokul döneminde seçim yapamadıkları, ilgi duymadıkları, zevk almadıkları ve sınırlarını zorlamayan eğitim ortamlarında bulunduklarında, kolay ve zahmetsizce başarıya ulaşırlar, zorlu görevlerden kaçarlar, var olan performanslarını gösteremeyebilirler (Reis ve McCoach, 2000). Bu nedenle genel eğitim sınıflarının hem üstün yetenekli çocuklar hem de normal gelişen çocukların potansiyellerini geliştirecekleri, sınıftaki etkinliklere yönelik ilgi, zevk alma ve sınırlarını zorlamaya ilişkin algılarını destekleyecek şekilde yapılandırılmasının önem taşıdığı söylenebilir. 


\section{Sinırlılıklar ve Öneriler}

Çalışma, Afyonkarahisar ilinde BİLSEM'e ve genel eğitim sınıflarına devam eden çocuklarla sınırlıdır. Bu çalışma farklı illerde öğrenim gören daha fazla sayıda çocuğa uygulanabilir.

Bu çalışma veri toplama aracı olarak "Sınıf Etkinliklerim Ölçeği"nin kullanılması ile sınırlıdır. Çalışma, çocukların sınıf içinde "Sınıf Etkinliklerim Ölçeği”ndeki alt boyutlar doğrultusunda gözlemlenerek ve çocukların öğretmenleri ile görüşme yapılarak nitel çalışmalarla desteklenebilir.

Çalışmada çocukların yüksek puan aldıkları görülmüş̧ür. Bu yüksek puanın oluşmasında etkili olabilecek faktörlere yönelik çalışma planlanabilir.

Üstün yetenekli çocukların bulunduğu sınıflarda sınıf etkinliklerinin daha ilgi çekici olması yönünde sınıf öğretmenleri planlama yapabilir.

Öğretmenlere üstün yetenekli çocuklara yönelik etkinlik planlama konusunda hizmet içi eğitim verilebilir.

\section{Kaynaklar}

Alexander, J. M., \& Schnick, A. K. (2008). Motivation. J. A. Plucker, \& C. M. Callahan (Ed.), Critical issues and practices in gifted education içinde (s. 423-447). Waco, TX: Prufrock Press.

Archambault, F. X., Westberg, K., Brown, S. B., Hallmark, B. W., Emmons, C. I., \& Zhang, W. (1993). Regular classroom practices with gifted students: Results of a national survey of classroom teachers. Storrs, CT: National Research Center on the Gifted and Talented.

Assouline, S. G., Colangelo, N., Ihrig, D., \& Forstadt, L. (2006). Attributional choices for academic success and failure by intellectually gifted students. Gifted Child Quarterly, 50(4), 283-294. https://doi.org/10.1177\%2F001698620605000402

Bacanlı, H., \& Sahinkaya, O. (2011). The adaptation study of academic motivation scale into Turkish. Procedia-Social and Behavioral Sciences, 12, 562-567. https://doi.org/10.1016/j.sbspro.2011.02.068

Bildiren, A. (2018). The interest issues of gifted children, World Journal of Education, 8(1), 17-26.

\section{https://doi.org/10.5430/wje.v8n1p17}

Brigandi, C. B., Siegle, D., Weiner, J. M., Gubbins, E. J., \& Little, C. A. (2016). Gifted secondary school students: The perceived relationship between enrichment and goal valuation. Journal for the Education of the Gifted, 39(4), 263-287. https://doi.org/10.1177\%2F0162353216671837

Brigandi, C. B., Weiner, J. M., Siegle, D., Gubbins, E. J., \& Little, C. A. (2018). Environmental perceptions of gifted secondary school students engaged in an evidence-based enrichment practice. Gifted Child Quarterly, 62(3), 289-305. https://doi.org/10.1177\%2F0016986218758441

Büyüköztürk, Ş., Kılıç-Çakmak, E., Akgün, Ö. E., Karadeniz, Ş., \& Demirel, F. (2008). Bilimsel araştırma yöntemleri. Ankara: Pegem Akademi Yayıncilık. 
Cash, R. (2011). Advancing differentiation: Thinking and learning skills for the 21st century. Minneapolis, MN: Free Spirit.

Csikszentmihalyi, M., Rathunde, K. R., \& Whalen, S. (1997). Talented teenagers: The roots of success and failure. Cambridge, MA: Cambridge University Press.

Davis, G. A., Rimm, S. B., \& Siegle, D. (2011). Education of the gifted and talented (6th Ed.). New Jersey, NJ: Pearson Education.

Deci, E., \& Ryan, R. (2008). Facilitating optimal motivation and psychological well-being across life's domains. Canadian Psychology/Psychologie Canadienne, 49(3), 17-23. https://doi/10.1037/0708$\underline{5591.49 .3 .262}$

Deniz, K. Z., \& Saranlı, A. G. (2017). Sınıf Etkinliklerim Ölçeği'nin (SEÖ) Türk kültürüne uyarlanması: Geçerlik ve güvenirlik çalışması. Eğitimde ve Psikolojide Ölçme ve Değerlendirme Dergisi, 8(2), 169-182. https://doi/10.21031/epod.291825

Ersoy, E., \& Başer, N. (2010). Probleme dayalı öğrenme sürecinin öğrenci motivasyonuna etkisi. Turkish Studies - International Periodical for the Languages, Literature and History of Turkish or Turkic, 5(4), 336-358.

Ertem, H. (2006). Ortaöğretim öğrencilerinin kimya derslerine yönelik güdülenme tür (içsel ve dişsal) ve düzeylerinin bazı değişkenler açısından incelenmesi. (Yüksek lisans tezi). https://tez.yok.gov.tr sayfasından erişilmiştir.

Frey, N., \& Fisher, D. (2010). Motivation requires a meaningful task. The English Journal, 100(1), 30-36.

Gentry, M., \& Gable, R. K. (2001). My Class Activities: A survey instrument to assess students'perceptions of interest, challenge, choice and enjoyment in their classrooms [Instrument]. Mansfield Center, CT: Creative Learning Press.

Gentry, M., Gable, R. K., \& Springer, P. (2000). Gifted and nongifted middle school students: Are their attitudes toward school different as measured by the new affective instrument, My Class Activities...? Journal for the Education of the Gifted, 24(1), 74-95. https://doi.org/10.1177\%2F016235320002400104

Gentry, M., \& Owen, S. V. (2004). Secondary student perceptions of classroom quality:Instrumentation and differences between advanced/honors and nonhonors classes. The Journal of Secondary Gifted Education, 16(1), 20-29. https://doi.org/10.4219\%2Fjsge-2004-464

Gentry, M., Rizza, M. G., \& Gable, R. K. (2001). Gifted students' perceptions of their class activities: Differences among rural, urban, and suburban student attitudes. Gifted Child Quarterly, 45, 115-129. https://doi.org/10.1177\%2F001698620104500205 
Hospel, V., \& Galand, B. (2016). Are both classroom autonomy support and structure equally important for students' engagement? A multilevel analysis. Learning and Instruction, 41, 1-10. https://doi.org/10.1016/j.learninstruc.2015.09.001

Karasar, N. (2009). Bilimsel araştırma yöntemi: kavramlar-ilkeler-teknikler. Ankara: Nobel Yayın Dağıtım.

McNabb, T. (2003). Motivational issues: Potential to performance. N. Colangelo, \& G. A. Davis (Ed.), Handbook of gifted education içinde (3rd Ed., s. 417-423). Boston: Allyn \& Bacon.

Molden, D. C., \& Dweck, C. S. (2000). Meaning and motivation. C. Sansone, \& J. M. Harackiewicz (Ed.), Intrinsic and extrinsic motivation: The search for optimal motivation and performance içinde (s. 131-159). San Diego, CA: Academic Press.

Ortiz, C. J. (2018). An experimental comparison of student motivation between two computational thinkingbased stem activities: vex-based automation and robotics and a quadcopter activity. (Master of Science), https://digitalcommons.usu.edu/etd/7193/ sayfasından erişilmiştir.

Park, S., \& Oliver E. (2009). The translation of teachers' understanding of gifted students into instructional strategies for teacheing science. Journal Science Teacher Education, 20(4), 333-351. https://doi.org/10.1007/s10972-009-9138-7

Pekrun, R., Goetz, T., Frenzel, A. C., Barchfeld, P., \& Perry, R. P. (2011). Measuring emotions in students' learning and performance: The Achievement Emotions Questionnaire (AEQ). $\begin{array}{llll}\text { Contemporary Educational 36-48 } & \text { 36logy, }\end{array}$ https://doi.org/10.1016/j.cedpsych.2010.10.002

Pereira, N., Bakhiet, S. F., Gentry, M., Balhmar, T. A., \& Hakami, S. M. (2017). Sudanese students' perceptions of their class activities: psychometric properties and measurement invariance of my class activities-Arabic language version. Journal of Advanced Academics, 28(2), 141-159. https://doi.org/10.1177\%2F1932202X17701881

Pereira, N., Peters, S. J., \& Gentry, M. (2010). My Class Activities instrument as used in Saturday enrichment program evaluation. Journal of Advanced Academics, 21(4), 568-593. https://doi.org/10.1177\%2F1932202X1002100402

Reid, E., \& Horváthová, B. (2016). Teacher training programs for gifted education with focus on sustainability. Journal of Teacher Education for Sustainability, 18(2), 66-74.

Reis, S. M., \& McCoach, D. B. (2000). The underachievement of gifted students: What do we know and where do we go? Gifted Child Quarterly, 44(3), 152-170. https://doi.org/10.1177\%2F001698620004400302

Renzulli, J. S. (1994). Schools for talent development: A comprehensive plan for total school improvement. Mansfield Center, CT: Creative Learning. 
Renzulli, J. S., Smith, L. H., White, A. J., Callahan, C. M., Hartman, R. K., \& Westberg, K. L. (2002). Scales for rating the behavioral characteristics of superior students (Rev. ed.). Mansfield Center, CT: Creative Learning Press.

Roeper A., \& Silverman L. (2009) Giftedness and moral promise. T. Cross, \& D. Ambrose (Ed.) Morality, ethics, and gifted minds. Boston, MA: Springer. https://doi.org/10.1007/978-0-38789368-619

Ryan, R. M., \& Deci, E. L. (2002). An overview of self-determination theory: An organismic dialectical perspective. E. L. Deci, \& R. M. Ryan (Ed.), Handbook of self-determination research içinde (s. 333). Rochester, NY: University of Rochester Press.

Sak, U. (2017). Üstün zekâlılar. Ankara: Vize Yayıncılık.

Saranlı, A. G. (2017). Eş zamanlı olmayan gelişimin üstün yetenekli çocuklardaki görünümü üzerine bir örnek olay çalışması. Ankara Üniversitesi Eğitim Bilimleri Fakültesi Özel Ĕ̆itim Dergisi, 18(1), 89-108. https://doi.org/10.21565/ozelegitimdergisi.300060

Schiefele, U. (1991). Interests, learning and motivation. Educational Psychologist, 26(3-4), 299-323.

Siegle, D., Rubenstein, L. D. V., Pollard, E., \& Romey, E. (2010). Exploring the relationship of college freshmen honors students' effort and ability attribution, interest, and implicit theory of intelligence with perceived ability. Gifted Child Quarterly, 54(2), 92-101. https://doi.org/10.1177\%2F0016986209355975

Singh, K., Granville, M., \& Dika, S. (2002). Mathematics and science achievement: Effects of motivation, interest, and academic engagement. The Journal of Educational Research, 95(6), 323332. https://doi.org/10.1080/00220670209596607

Webb, J. T., Gore, J. L., Amend, E. R., \& DeVries, A. (2007). A parent's guide to gifted children. Scottsdale, AZ: Great Potential Press.

Westberg, K. L., Archambault, F. X., Dobyns, S. M., \& Salvin T. J. (1993). An observational study of instructional and curricular practices used with gifted and talented students in regular classrooms. Storrs, CT: The National Research Center on the Gifted and Talented.

Wigfield, A., \& Eccles, J. S. (2000). Expectancy-value theory of achievement motivation. Contemporary Educational Psychology, 25, 68-81. https://doi.org/10.1006/ceps.1999.1015

Wright, B. L., \& Ford, D. Y. (2017). Untapped potential: Recognition of giftedness in early childhood and what professionals should know about students of color. Gifted Child Today, 40(2), 111-116. https://doi.org/10.1177\%2F1076217517690862 
Yang, Y., Gentry, M., \& Choi, Y. O. (2012). Gifted students' perceptions of the regular classes and pullout programs in South Korea. Journal of Advanced Academics, 23(3), 270-287. https://doi.org/10.1177\%2F1932202X12451021

\section{Extended Summary}

Motivation is the source of children's success. Motivation is all of the internal and external factors that enable children to acquire a purposeful behavior (Ertem, 2006). It is stated that learning and motivation are related concepts (Bacanlı \& Şahinkaya, 2011). Because of that, the learning environment offered to children is highly effective on children's motivations (Gentry \& Gable, 2001). Teachers should make some changes to increase the motivation of children. These changes can be listed as enabling children to enjoy class activities, have fun and challenge (Gentry \& Gable, 2001). It is said that the changes made to increase motivation are as important for gifted children as normal children (Pereira, Bakhiet, Gentry, Balhmar, \& Hakami, 2017). Gifted children are defined as children who perform better in some developmental areas than their peers. They can demonstrate different developmental characteristics according to their peers (Davis, Rimm, \& Siegle, 2011). While they demonstrat outstanding ability in some areas of development, they are typical in some areas of development and lower in some areas of development (Saranl1, 2017). In order to support the different developmental characteristics of gifted children in general education classes, it is necessary to present different learning environments, enrich the program, and differentiate methods and techniques (Park \& Oliver, 2009; Reid \& Horvathova, 2016). In this way, it has been emphasized that the gifted children should be offered programs and their fields of interest, including their interest by challenging and enjoyment in their general education classes (Reid \& Horvathova, 2016; Renzulli, 1994; Wright \& Ford, 2017). Gifted children make more efforts to learn fields in their interests (Csikszentmihalyi, Rathunde, \& Whalen, 1997; Renzulli et al., 2002), so they learn more easily (Singh, Granville, \& Dika, 2002). When gifted children are offered the opportunity to choose according to their field of interests, children have control over their own learning. In this way, the inner motivation of the children and their participation in the class increase (Deci \& Ryan, 2008; Ryan \& Deci, 2002). Associated with the field of interest, the concept of challenge affects the motivation and learning of gifted children. Challenging is the effort of children to go one step further than what they can do. Gifted children try to make higher skills by challenging their abilities and can support their development by challenging their own limits (Assouline, Colangelo, Ihrig, \& Forstadt, 2006; McNabb, 2003). When gifted children are supported to make choices, it is stated that children participate better in lessons (Hospel \& Galand, 2016), are motivated more (Frey \& Fisher, 2010), and their ability to make decisions on their own are increasing (Gentry \& Owen, 2004). Another concept associated with choice and interest is enjoyment (Pereira, Peters, \& Gentry, 2010). When the activities are structured by children toward the fields of interest, to 
challenge their limits on the field they choose, children enjoy the activities (Cash, 2011). It is concluded that when class activities include children's interests and the opportunity to choose, children's motivation to learn will be positively affected and they will challenge their limits and enjoy the process. In conclusion, it was aimed to determine and compare the perceptions of gifted and typical developing children attending primary school about classroom activities in the study. For this purpose, answers were sought to the following questions:

1. What is the level of perceptions of gifted and typical developing children about classroom activities?

2. Is there a statistically significant difference between the perceptions of gifted and typical developing children about classroom activities?

This is a descriptive study designed in a scanning model. The study group of the research consists of 289 children attending Science and Art Centre (BİLSEM) and primary schools affiliated to Afyonkarahisar Provincial Directorate of National Education in the fall semester of the 2019-2020 academic year. My Class Activities Survey was used as the data collection tool. The scale was developed by Gentry and Gable (2001) and adapted to Turkish by Deniz and Saranlı (2017) in order to determine children's perceptions about being interested in, enjoying, challenging and making choices for activities in the classroom. The scale consists of 32 items and four sub-dimensions: interest, choice, challenge and enjoyment. Percentage, frequency and Mann Whitney U Test were used in the analysis of the data.

The scores obtained from the scale were found 3.59-4.47 in gifted children and 3.79-4.11 in typical developing children. When the scores obtained by the gifted and typical developing children from the sub-dimensions and the total of My Class Activities Survey were examined, it was seen that there was no statistically significant difference ( $p>05)$. When the scores of gifted and typical developing children received from My Class Activities Survey were compared on the basis of items, it was found that there were statistically significant differences in favor of children with typical development in items $2,4,5,9$ and $21(\mathrm{p}<.05)$. There was no statistically significant difference in other items ( $p>.05)$.

As a result of the study, it was determined that the perceptions of gifted and typical developing children towards class activities were at high level. In this study, the high scores that the children got from the scale, showed that the general education classes were interesting, enjoyable, selectable and challenging their limits. It is considered that this is due to the use of technological equipment in educational environments, the ease of access to materials, and the realization of education taking into account the individual differences of the children. When the scores of the children from the scale were analyzed on the basis of items, it was observed that there was a 
significant difference in favor of children who normally developed in the items of interest (item 2, 4, 5), pushing the boundaries (item 9) and choice (item 21). This result is not surprising considering the fact that gifted children are bored in general education classes, do not enjoy themselves, are not interested in the literature. It can be said that it is important to structure the class activities in such a way that both gifted and typical developing children will develop their potential and support their perceptions about interest, enjoyment and pushing the limits for activities in the classroom.

\section{Araştırmacıların Katkı Oranı Beyanı}

$\mathrm{Bu}$ araştırmada birinci yazar; makalenin giriş, verilerin analizi, tartışma ve sonuç kısımlarına, ikinci yazar; makalenin giriş, verilerin toplanması ve yöntem kısımlarına katkıda bulunmuştur.

\section{Destek ve Teşekkür Beyanı}

Bu araştırmada herhangi bir kurum, kuruluş ya da kişiden destek alınmamıştır.

\section{Çatışma Beyanı}

Araştırmacının araştırma ile ilgili diğer kişi ve kurumlarla herhangi bir kişisel ve finansal çıkar çatışması yoktur.

\section{Etik Kurul Beyanı}

$\mathrm{Bu}$ araştırma Afyon Kocatepe Üniversitesi Sosyal ve Beşeri Bilimleri Araştırma ve Yayın Etiği Kurulunun 11.12.2019 tarih ve 137 sayılı onayı ile yürütülmüştür. 